\title{
Сравнительные характеристики отечественных и импортных влагозащитных покрытий
}

УДК 621.3.049.75:621.793 | ВАК 05.27.06

\author{
Н. Левкина ${ }^{1}$, А. Медведев, д. т.н. ${ }^{2}$
}

\begin{abstract}
Влагозащитные покрытия призваны уменьшить влияние внешних воздействующих факторов (ВВФ) на деградационные процессы в радиоэлектронной аппаратуре. При этом они не должны оказывать отрицательного влияния на ЭРИ, печатные платы и проводники, должны поддерживать хорошие электроизоляционные характеристики диэлектрических оснований печатных плат в условиях увлажнения и обладать хорошими технологическими качествами. Предыдущая публикация авторов на эту тему [1] была посвящена рассмотрению свойств и особенностей применяемых сегодня влагозащитных покрытий различных классов. В данной статье приводится сравнительная характеристика основных типов отечественных и зарубежных покрытий, наиболее часто применяемых в российской электронной промышленности.
\end{abstract}

\section{ОТЕЧЕСТВЕННЫЕ ВЛАГОЗАЩИТНЫЕ ПОКРЫТИЯ}

Из отечественных влагозащитных покрытий в российской электронной промышленности, как правило, используются лаки на основе эпоксидных смол с сополимерами:

- УР-231 и УР-231Л ТУб-21-14-90;

- $\ni П-730$ ГОСТ 20824;

- ЭП-9114 ТУ 6-21-3-89.

Покрытия на основе лаков УР-231 получили наибольшее распространение и хорошо зарекомендовали себя в аппаратуре специального назначения. Ур-231 является двухкомпонентным материалом с добавлением растворителей для получения нужной вязкости. Получаемое покрытие обладает высокими электроизоляционными свойствами, позволяет эксплуатировать изделия в диапазоне температур от -60 до 120 C в условиях тропической влажности.

Покрытие состоит из полуфабрикатного алкидноэпоксидного лака Ур-231 и отвердителя дгу. Полуфабрикат представляет собой раствор алкидно-эпоксидной смолы Э-30 с добавлением тунгового масла, отвердитель Дгу - это 70\%-ный раствор диэтиленгликольуретана (Дгу) в циклогексаноне [2]

Компоненты необходимо смешивать непосредственно перед применением. Приготовленное покрытие имеет время жизни 5 4, нанесение на поверхность производится поливом, окунанием, окунанием

МАИ (НИУ), аспирант, n.levkina@yandex.ru.

МАИ (НИу), профессор, medvedevam@ьk.ru. с последующим центрифугированием, пневматическим распылением, кистью; возможность нанесения на автоматических установках селективной влагозащиты отсутствует.

Толщина однослойного покрытия 10-20 мкм, рекомендуемое количество слоев 2-4, оптимальная толщина многослойного покрытия 40-55 мкм

Основным компонентом лака УР-231, придающим ему водоотталкивающие свойства, является тунговое масло, а эпоксидная составляющая нужна главным образом для закрепления покрытия на поверхности печатного узла. Тунговое масло полимеризуется за счет поглощения кислорода воздуха (так же, как олифа) в течение суток. Поэтому, независимо от того, что пленка лака Ур-231 твердеет в термошкафу за несколько часов, для полного отверждения покрытия с тунговым маслом требуются сутки.

В советское время поставщиком тунгового масла являлась Грузия, которая после распада СССР вырубила все тунговые рощи. В этой неожиданно возникшей ситуации поставщики УР-231 решили заменить тунговое масло на льняное, не известив об этом потребителей. Начались массовые отказы аппаратуры при повышенной влажности, поскольку отвердевшее льняное масло в таких условиях гидролизуется, и лаковая пленка теряет влагозащитные свойства. Тогда тунговое масло стало импортироваться из Италии, в последнее время из Китая. Но рецептура с льняным маслом закрепилась в композиции ур-231Л с ограниченным использованием. 
Тот факт, что тунговое масло требует особого подхода к его отверждению - окислительной полимеризации, - наряду с невозможностью автоматического нанесения делает лак Ур-231 не соответствующим современным требованиям по технологичности, что вызвало активизацию поиска других влагозащитных материалов.

Лак эП-730 является двухкомпонентным и представляет собой раствор эпоксидной смолы Э-41 в смеси органических растворителей с добавлением отвердителя. Применяется для защиты изделий, эксплуатируемых в различных климатических районах, работающих в условиях повышенной влажности, температуры, действия растворов щелочей, спирто-бензиновой смеси.

В качестве отвердителя используется "Отвердитель №1» [3]. Его слабая сторона заключается в высокой токсичности и раздражающем действии на кожные покровы. Недостаток отвердителя, так же как и его избыток, обычно приводит к ухудшению качества получаемого покрытия. Следствие - необходимость тщательного соблюдения рецептуры.

Покрытие допускает одно-, двух- или трехслойное нанесение. При однослойном нанесении толщина высушенной пленки должна быть 18-22 мкм.

Приготовленное покрытие имеет время жизни 8 ч, во время использования готового раствора допускается двукратное разбавление лака до рабочей вязкости. Лак наносится методом распыления, окунанием, поливом или кистью и не допускает возможности применения автоматических установок селективной влагозащиты.

Ряд предприятий отказывается от применения лака ЭП-730 из-за наличия в его составе активных растворителей, взаимодействующих с материалом основания печатной платы, вызывая его набухание. Это может приводить к крайне неприятным последствиям. Дело в том, что лак отвердевает в первую очередь по периферии корпуса микросхемы и тем самым исключает возможность выхода растворителей из-под корпуса. Задержавшиеся под корпусом микросхемы растворители переходят в объем диэлектрика, вызывая его набухание, то есть его расширение. Если под корпусами микросхем при проектировании размещают переходные отверстия, то их металлизация лопается под действием этого расширения.

эп-9114 - широко применяемый эпоксидный лак, также двухкомпонентный, представляющий собой раствор эпоксидной смолы ЭД-20 в смеси растворителей с добавлением пластификатора. В качестве отвердителя в этом лаке используется ИМЭП-1. Полимеризованное покрытие позволяет длительно эксплуатировать изделия в широком диапазоне температур, от -60 до $125^{\circ} \mathrm{C}$, во всех климатических зонах без ограничений.
Жизнеспособность приготовленной смеси - не менее 3 ч. Лак предполагает однослойное нанесение методом окунания или полива.

Технические характеристики лаков (ЭП-730 и ЭП-9114) почти одинаковы, однако ЭП-9114 выгодно отличается высоким содержанием нелетучих компонентов (около 85\%).

Рассмотренные влагозащитные покрытия имеют ряд недостатков. К ним относятся относительно небольшое время жизни приготовленного (разведенного) лака, а также токсичность материалов из-за входящих в их состав смол, растворителей и применяемых отвердителей, которые оказывают наркотическое действие на нервную систему, раздражают кожу, слизистую оболочку глаз, верхних дыхательных путей. Это приводит к необходимости все работы с изготовлением и применением лаков производить в местах, специально оборудованных приточно-вытяжной вентиляцией, и соблюдать повышенные меры личной безопасности работников (специальная одежда, перчатки, респиратор, защитные очки и пр.).

Для лаков ЭП-730 и ЭП-9114 особенно серьезным недостатком является неудачный подбор растворителей. Кроме свойственного лаку ЭП-730 эффекта разрыва металлизации отверстий под микросхемами из-за набухания диэлектрика, оба этих материала имеют еще одно негативное свойство: отвердевшая пленка лака препятствует выходу растворителей, проникших в объем диэлектрического основания платы. В последующей эксплуатации при повышенных температурах растворители, переходя в парообразное состояние, распирают конструкцию печатного узла и могут отслаивать лаковую пленку, создавая впечатление плохой адгезии лака к поверхности платы.

Важной проблемой при использовании эпоксидных влагозащитных покрытий является обеспечение ремонтопригодности печатных узлов. Обычно она проявляется при необходимости замены электронных компонентов на плате, покрытой влагозащитным лаком. При этом трудности возникают не столько при удалении лаковых пленок, сколько при последующей очистке мест ремонта и их повторной лакировке в неприспособленных для этого условиях.

Разнообразные приемы удаления лаковых покрытий описаны в стандартах $[4,5]$. Одним из лучших способов решения этой задачи является метод абразивного удаления.

Процесс удаления микроабразивом подробно рассмотрен в статье [6]. Он основан на абразивном воздействии на печатный узел потока быстро движущейся смеси частиц специального абразива и воздуха, который проходит через форсунку, закрепленную на наконечнике, управляемом вручную или автоматическим 
манипулятором. Это позволяет направлять смесь в точно определенное место на печатной плате для снятия покрытия. Основные преимущества метода:

- высокая скорость очистки печатного узла;

- быстрое и эффективное удаление отечественных двухкомпонентных лаков, а также париленовых покрытий и лаков, отверждаемых УФ-облучением;

- селективное удаление необходимых участков покрытия;

- отсутствие необходимости применения растворителей;

- исключение повреждений компонентов, проводящего рисунка, паяных соединений, паяльной маски, маркировки и т. п.

В настоящий момент, помимо импортного оборудования, на рынке представлена отечественная установка "Борей», спроектированная специалистами Группы компаний Остек специально для применения в электронике и предназначенная для удаления различных видов влагозащитных покрытий с печатных узлов микроабразивным методом [7]

Технологи производств, применяющих отечественные эпоксидные покрытия, умеют так или иначе решать связанные с ними проблемы. Однако остается один ключевой недостаток, становящийся сегодня все менее терпимым: невозможность автоматического селективного нанесения. Передовые предприятия отрасли ориентированы на автоматизацию сборки печатных узлов; это связано в первую очередь с тем, что автоматизированный процесс обладает более стабильными характеристиками, чем процесс, выполняемый в ручном режиме. Во многих случаях автоматизация позволяет сократить время выполнения технологической операции, повысить производительность, снизить стоимость изделия, увеличить точность нанесения влагозащитного материала [8].

Главным препятствием для автоматизации процесса нанесения лаковых покрытий является короткое технологическое время жизни композиций: ур-231 - 54 , ЭП-730 - 8 ч, ЭП-9114 - 3 ч. Это ограничение исключает возможность организации непрерывного цикла покрытия изделий, что привело к необходимости поиска новых, отвечающих требованиям автоматизации составов влагозащитных покрытий по типу импортных.

\section{ПОЛИПАРАКСИЛИЛЕНОВЫЕ ВЛАГОЗАЩИТНЫЕ ПОКРЫТИЯ}

Полипараксилиленовое покрытие (ППКП) обеспечивает надежность изделий, работающих в условиях воздействия повышенной влажности и температуры (рабочий диапазон температур от -100 до $150{ }^{\circ} \mathrm{C}$ на воздухе и до $400{ }^{\circ} \mathrm{C}$ при отсутствии кислорода), биологических, химических и других факторов.
Впервые семейство покрытий под общим названием «парилен» применила в 1961 году фирма Union Carbide (США). С 1976 года парилен широко используется в передовых западных технологиях авиакосмической, военной и промышленной техники, в изделиях радиои электротехнического назначения [9]. Принцип формирования париленовых пленок, их преимущества и недостатки были подробно рассмотрены в статье [1].

Разработка отечественной технологии получения покрытия этого типа начиналась в конце 1980-х годов в рамках комплексной программы МНТК «Радиотехномаш". В 1990-е разработка временно прекратилась, и лишь в 2001 году ООО «Базальт» предприняло попытку восстановления производства. Сегодня это предприятие предлагает отработанную отечественную технологию получения ППКП для влагозащиты, электроизоляции и капсулирования элементов радиоэлектронной аппаратуры и изделий микроэлектроники.

Недостатком отечественной технологии получения полипараксилиленовых покрытий является необходимость покупки дорогостоящего оборудования. Кроме того, для получения ППКП применяются в основном исходные продукты зарубежного производства (США, Япония). Это приводит к увеличению стоимости покрытия, а также сопряжено с рисками, не связанными с экономикой и технологией.

Насколько известно авторам, сегодня в России, за исключением ППКП, нет новых покрытий, скольконибудь широко применяемых в производственной практике. Одна из проблем выбора из доступных импортных влагозащитных покрытий новых видов состоит в недостаточной полноте имеющейся информации об их технических характеристиках. В таких условиях для подтверждения возможности использования импортных покрытий с целью замены отечественных необходимо проведение полного цикла испытаний, позволяющего определить типы материалов, в наибольшей степени удовлетворяющих требованиям, предъявляемым к аппаратуре, - особенно если речь идет о военной промышленности.

Полный цикл испытаний полимерных покрытий имеет высокую стоимость и требует больших затрат времени, которые определяются условиями применения изделия в зависимости от классификационной группы (здесь и далее имеется в виду классификация изделий военной техники в соответствии с ГОСТ РВ 20.39.304-98). В этой связи, для сокращения расходов, целесообразно прежде всего провести анализ рынка импортных покрытий с целью отбора наиболее подходящих по характеристикам. Для отобранных по результатам анализа материалов следует организовать предварительные испытания, задача которых-исключить покрытия, которые не смогут удовлетворить 
требования, предъявляемые в ходе дальнейших испытаний к изделиям, защищенным этими покрытиями.

На этапе предварительных испытаний в первую очередь необходимо обращать внимание на диэлектрические и влагозащитные свойства, которые должны быть выше, чем свойства диэлектриков печатных плат, и не хуже свойств широко применяемого в настоящее время лака УР-231.

После проведения сотрудниками кафедры 307 ("Технологии приборостроения») во взаимодействии со специалистами промышленности анализа технической информации для предварительных испытаний был отобран ряд марок покрытий, относящихся почти ко всем классам материалов, используемым сегодня для этой цели в зарубежной электронике, а именно акриловые (acrylic, AR), уретановые (urethane, UR), кремнийорганические (silicone, SR) покрытия, а также покрытия на основе сочетания этих классов полимеров.

Изучение импортных материалов, поставляемых на отечественный рынок, показало, что наиболее широко представлены продукты компаний HumiSeal, Dow Corning и CRAMOLIN. Ниже рассмотрены акриловые и уретановые покрытия на основе растворителей или на водной основе и покрытия ультрафиолетового отверждения, предлагаемые фирмой HumiSeal, силиконовые влагозащитные покрытия, производимые фирмой Dow
Corning, а также уретановое и акриловое покрытия фирM CI CRAMOLIN

\section{ВЛАГОЗАЩИТНЫЕ ПОКРЫТИЯ КОМПАНИИ HumiSeal}

Компания Humiseal разработала более 150 различных типов влагозащитных покрытий. Все ее продукты пригодны для большинства групп условий эксплуатации, установленных международными стандартами; кроме того, существуют покрытия, разработанные для применения в условиях особых сочетаний ВВФ [10]. Все рассмотренные ниже покрытия Humiseal являются однокомпонентными (то есть не требуют предварительного смешивания компонентов и поставляются готовыми к применению), позволяют эксплуатировать изделия в широком диапазоне температур: от -65 до $125^{\circ} \mathrm{C}$, сертифицированы по стандарту MIL-I-46058C (производителем заявлена стойкость к воздействию 50 циклов изменения температуры на рабочем диапазоне в соответствии с указанным стандартом) и соответствует всем требованиям IPC-СC-830.

Немаловажным достоинством покрытий HumiSeal является наличие в их составе флюоресцирующих агентов, которые позволяют проконтролировать качество нанесенной и отвержденной пленки в ультрафиолетовом свете.

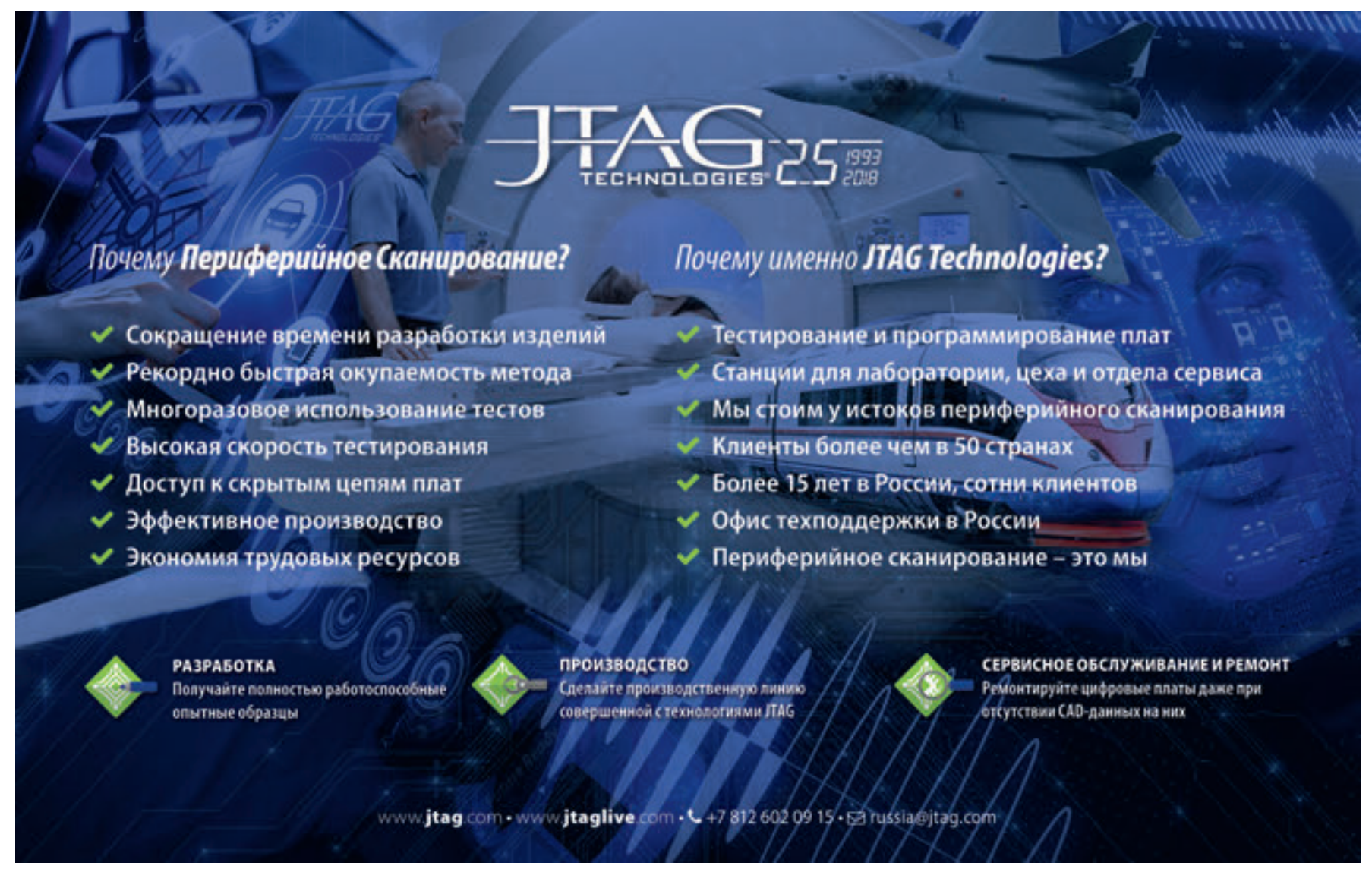


Акриловые покрытия HumiSeal находят широкое применение благодаря простоте использования Их преимуществами считаются превосходная защита от повышенной влажности, быстрое отверждение при нагреве, хорошая устойчивость к плесневым грибкам, высокая эластичность в широком диапазоне температур, наилучшая адгезия к материалам печатного узла и высокая ремонтопригодность отвержденной пленки, в том числе в процессе наладки устройства [11].

В настоящий момент на российском рынке представлены следующие акриловые покрытия HumiSeal: 1H20AR1 на водной основе, 1B73 и 1R32A-2 на основе растворителей. Указанные покрытия имеют схожие характеристики, поэтому достаточно будет рассмотреть наиболее часто используемое покрытие 1В73.

1 1873 является быстро полимеризующимся материалом, обеспечивающим защиту от влажности и негативных воздействий окружающей среды; покрытие демонстрирует отличную гибкость и адгезию и легко поддается ремонту [12]. Время первичной сушки на отлип (степень высыхания покрытия, при которой оно перестает быть липким при прикосновении) - 30 мин (время первичной сушки определяется в соответствии с методом 4061 Федерального стандарта 141D [13]). Дальнейшая полимеризация возможна на открытом воздухе (24 4) или в термошкафу при температуре $76^{\circ} \mathrm{C}$ (2 4). За это время покрытие приобретает свои финальные физические и химические свойства.

Снятие покрытия осуществляется с использованием растворителя Stripper 1080

Уретановые покрытия HumiSeal имеют высокую химическую стойкость, пригодны для эксплуатации в широком диапазоне температур, устойчивы к соляному туману и к плесневым грибкам, быстро отверждаются при нагреве, отличаются высокой технологичностью и ремонтопригодностью.

Одним из наиболее распространенных представителей данного типа является уретановое покрытие 1A33, широко используемое в военной технике и авиации. Время его первичной сушки на отлип - 15 мин, дальнейшая полимеризация возможна в нормальных условиях на открытом воздухе (30 дней) или при повышенной температуре (30 ч при $76^{\circ} \mathrm{C}$ или 204 при $88^{\circ} \mathrm{C}$ ) [14].

Локальный ремонт модулей с полимеризованным покрытием производится термическим методом (с помощью жала паяльника). Для полного или частичного (с большой площади) удаления покрытия применяется специальный растворитель Stripper 1063.

Благодаря возможности использования разбавителей (Thinner) для корректировки вязкости уретановые и акриловые покрытия HumiSeal допускают нанесение большинством из существующих методов (кисть, окунание, распыление, автоматизированное селективное нанесение).
Для каждого покрытия имеется свой рекомендованный производителем разбавитель. Для некоторых марок рекомендуется использование разных разбавителей для каждого из методов нанесения. Так, например, при нанесении погружением для уменьшения вязкости с лаком 1В73 используется разбавитель Thinner 73, а с 1А33 разбавитель Thinner 503. При выборе метода нанесения кистью возможно незначительное добавление разбавителя HumiSeal 73 для 1 B73 и Thinner 503 для 1А33. Следует иметь в виду, что в этом случае однородность покрытия зависит от опыта оператора и плотности расположения компонентов на плате.

В другом варианте - при нанесении с помощью стандартного оборудования для селективного нанесения или ручного распыления, - чтобы получить равномерное покрытие, рекомендуется добавлять разбавитель Thinner 73 для 1B73 в соотношении 1:1 по объему, а для 1А33 - разбавитель Thinner 521 в соотношении 4 : 1. На практике надо учитывать, что во время нанесения испарение растворителя вызывает увеличение вязкости. В связи с этим оптимальное соотношение лака и разбавителя, так жекак и давление распыления, должны быть предварительно определены технологом, поскольку они зависят от характеристик конкретного типа оборудования и навыков исполнителя $[12,14]$. Рабочее место должно быть оснащено приточно-вытяжной вентиляцией, чтобы распыляемые вещества не попадали на оператора.

Рекомендуемая толщина покрытия для лаков 1 1В73 и 1А33 - 25-75 мкм, рекомендуемое количество слоев -1 .

Кроме акриловых и уретановых покрытий, компания Humiseal предлагает гибридные покрытия, в частности, UV40 - смесь полиакрилатов и полиуретанов (ARUR). На сегодня это одни из самых быстрополимеризующихся материалов, представленных на мировом рынке влагозащитных покрытий. В их состав не входит растворитель, а отверждение лаков осуществляется за счет воздействия УФ-облучения.

Разновидности этого покрытия - UV40, UV40-250, UV40 HV - различаются по вязкости; особым свойством материала UV40 Solar является стойкость к ультрафиолету: он не желтеет при воздействии УФ-излучения.

Одним из ключевых преимуществ покрытия UV-40 является средний уровень его вязкости. Это позволяет быстро и равномерно покрывать компоненты и гарантирует равномерное распределение материала по всей поверхности печатного узла. Покрытие обладает высокой химической стойкостью, твердостью и эластичностью. Оно создает надежный барьер от проникновения влажности и соляного тумана на поверхность печатного узла, имеет хорошую гибкость влагозащитной пленки в широком диапазоне температур и достаточную толщину покрытия даже на острых кромках компонентов [15]. 

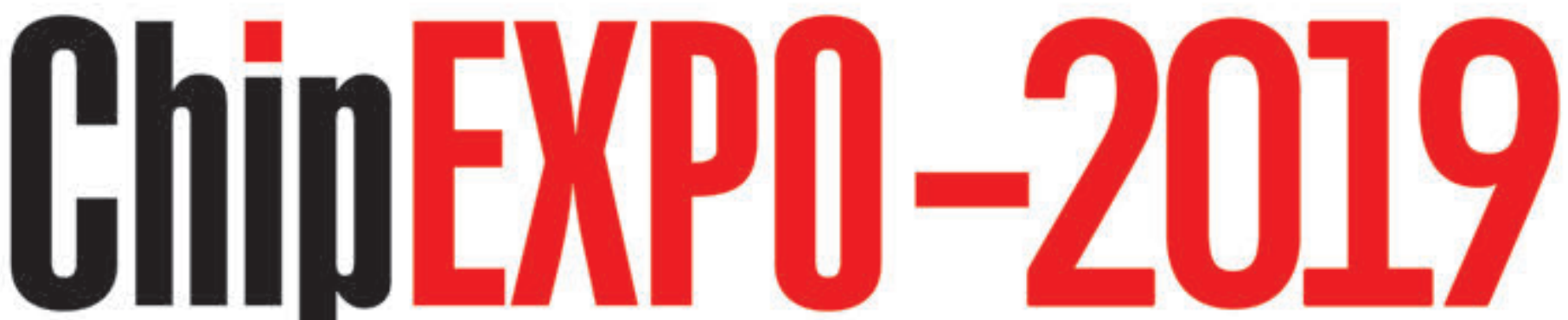

\section{КОМПОНЕНТЫ | ОБОРУДОВАНИЕ | ТЕХНОЛОГИИ}
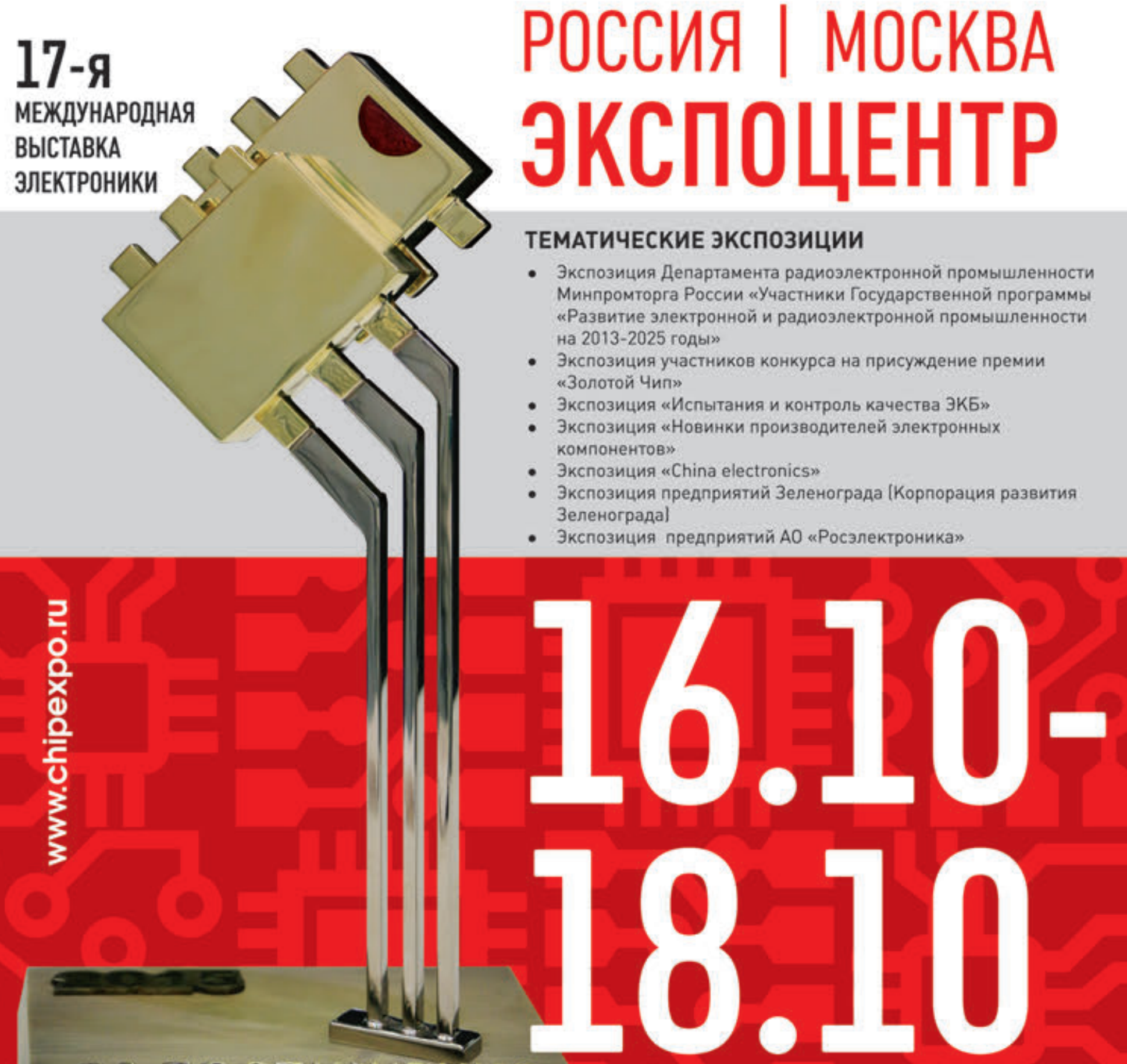

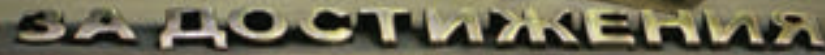
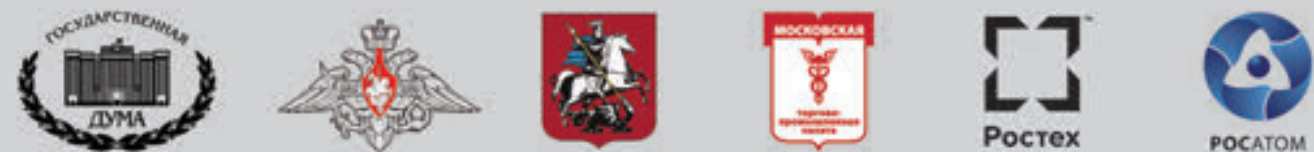
HumiSeal UV40 имеет двойной механизм отверждения: на первом этапе происходит полимеризация в печах ультрафиолетового отверждения в течение 10-30 с (в зависимости от мощности УФ-излучателей) после чего основной массив покрытия приобретает все физические свойства и химическую стойкость. На втором этапе происходит дополимеризация покрытия в теневых зонах за счет влажности окружающего воздуха; в нормальных условиях отверждение покрытия в теневых зонах происходит через 2-3 дня. Процесс дополимеризации может быть ускорен в термошкафу при увеличении температуры (до 60-80 $\mathrm{C}$ ) и поддержании повышенной влажности, тогда он занимает 2 4. Большим преимуществом является возможность проведения дополимеризации в процессе проведения испытаний изделий на воздействие повышенной влажности [16].

Humiseal UV40 допускает нанесение с помощью стандартного оборудования для селективного нанесения или ручного нанесения распылением без использования разбавителей. Необходимо учитывать, что для предотвращения преждевременной полимеризации рекомендуется использовать для распыления сухой воздух (сухой инертный газ), а также осуществлять контроль температуры материала в расходной емкости технологической установки.

Данное покрытие непригодно для использования в ваннах погружения. Ручное нанесение кистью может применяться только для доработки или исправления дефектов, при этом для обеспечения возможности многократного использования инструмента он должен быть очищен растворителем сразу после завершения операции.

Отвержденная пленка UV-40 отличается повышенной химической стойкостью и требует значительно больших усилий для удаления по сравнению с остальными покрытиями. Локальное удаление производится термическим или механическим методом. Удаление покрытия с большой площади возможно с помощью специального растворителя Stripper 1100. Для очистки оборудования после использования рекомендуется применять Thinner 521 или 521EU.

По результатам анализа данных по покрытиям, выпускаемым фирмой HumiSeal, следует отметить следующие их преимущества:

- большое время жизни приготовленного покрытия при комнатной температуре. Время жизни напрямую зависит от процесса нанесения. Например, в рабочей емкости установки селективного нанесения покрытие 1 А33 может находиться в приготовленном состоянии не менее двух недель;

- отсутствие необходимости в растворителях, что делает покрытие более удобным в применении, безопасным для окружающей среды, дает высокую скорость отверждения и сокращает технологическое время с момента нанесения до обретения пленкой конечных свойств;

- однокомпонентный состав - продукт поставляется готовым К применению;

- возможность применения методом селективного нанесения, который позволяет обеспечить высокую повторяемость процесса;

- ремонтопригодность модулей после нанесения покрытий (возможность локального ремонта модулей без использования дополнительных материалов) и удобство полного снятия покрытий;

- удобство контроля полученного покрытия (контроль качества нанесенной и отвержденной пленки в ультрафиолетовом свете);

- хорошая адгезия.

Следует, однако, помнить, что, хотя продукты Humiseal имеют хорошую адгезию к материалам печатного узла, качество и надежность покрытий чрезвычайно сильно зависят от чистоты поверхности. Поверхности печатных узлов, на которые будет наноситься влагозащитное покрытие, должны быть подвергнуты тщательной отмывке и сушке, так как даже остатки "безотмывочных" неактивных флюсов могут привести к ухудшению адгезии, проблемам с нанесением покрытия и его полимеризацией, к значительному ухудшению свойств покрытия, вплоть до сведения на нет его защитных функций [17].

\section{ВЛАГОЗАЩИТНЫЕ ПОКРЫТИЯ CRAMOLIN}

Немецкая компания LLC \& Co. KG (ITW Spraytec), выпускающая продукцию под брендом CRAMOLIN, является производителем специальных материалов для защиты, ремонта, технического и сервисного обслуживания оборудования, заслужившим одобрение профессионалов в области электротехники и электроники во всем мире.

На рынке представлены различные типы влагозащитных покрытий данной марки. Все покрытия пригодны для большинства условий эксплуатации. Основными представителями являются:

- акриловый лак PLASTIK;

- полиуретановый лак URETHANE CLEAR;

- полиуретановый лак URETHANE RED;

- термостойкий силиконовый лак ISOTEMP;

- графитовый токопроводящий лак GRAPHITE;

- светочувствительный лак POSITIV RESIST;

- токопроводящий лак EMILAC.

Все перечисленные покрытия выпускаются в виде спреев, готовых к применению; с одной стороны, это очень удобно при ручном нанесении, но с другойделает невозможным их использование в установках 
селективного нанесения. Ниже рассмотрены акриловое и уретановое покрытия фирмы CRAMOLIN, выпускаемые в стандартных канистрах и пригодные для нанесения традиционными способами.

Акриловый лак PLASTIK - прозрачный акриловый лак, имеет высокие диэлектрические характеристики и рекомендован для защиты поверхностей из пластика, металла, дерева, стекла, картона и т.д. Покрытие не трескается при изгибании поверхности, защищая ее от механических повреждений, и пригодно для эксплуатации при температурах от -70 до $120^{\circ} \mathrm{C}$. Время первичной сушки на отлип составляет 15 мин. Дальнейшая полимеризация возможна на открытом воздухе в течение 48 ч. Локальный ремонт модулей с полимеризованным покрытием производится термическим методом (с помощью жала паяльника).

Oснова CRAMOLIN PLASTIK - акриловая смола, при распылении образующая прозрачный глянцевый защитный слой, который предохраняет любые поверхности от коррозии, пыли, негативного воздействия разбавленных кислот, щелочей, спиртов, солей, от заплесневения, легких механических воздействий, а также других разрушающих факторов окружающей среды. Содержит УФ-индикатор для контроля качества покрытия.

Для данного покрытия предусмотрен растворитель, предназначенный для разведения и уменьшения вязкости.

Полиуретановый лак URETHANE CLEAR - уретановый однокомпонентный лак. Формирует на поверхности прочную водоотталкивающую и электроизолирующую пленку с высокими показателями адгезии, предназначен для эксплуатации в широком диапазоне температур (от -40 до $130^{\circ} \mathrm{C}$ ). Лак разработан для электрической изоляции и защиты поверхностей от коррозии, химических, термических и легких механических повреждений. Противостоит влаге, плесени, кислотам, щелочам, соляному туману, пару, спиртам, растворителям, содержащим хлор. Время первичной сушки на отлип - 15-20 мин. Дальнейшая полимеризация возможна на открытом воздухе (48 ч) или при повышенной температуре (30 мин при $\left.60^{\circ} \mathrm{C}\right)$. Нанесение второго слоя возможно через 244.

Для данного покрытия также предусмотрен растворитель, предназначенный для разведения и уменьшения вязкости.

\section{СИЛИКОНОВЫЕ ВЛАГОЗАЩИТНЫЕ ПОКРЫТИЯ Dow Corning}

Компания Dow Corning (США) является мировым лидером в области инновационных технологий на основе кремнийорганических материалов. Влагозащитные покрытия Dow Corning имеют повышенную термостойкость: силиконы надежно работают при длительном воздействии температур от -45 до $200^{\circ} \mathrm{C}$. Многие силиконы могут даже выдерживать кратковременное воздействие температур до $250^{\circ} \mathrm{C}$. Еще одним большим преимуществом данных покрытий является отсутствие внутренних напряжений - следствие эластичности образуемой ими пленки [11]

Силиконовые влагозащитные покрытия представлены тремя семействами продуктов.

Эластомерные влагозащитные покрытия, отверждаемые при комнатной температуре и не содержащие растворителей. Для полимеризации необходима атмосферная влага. Отверждение может быть ускорено незначительным нагреванием. После отверждения, помимо выполнения обычных защитных функций, типичных для влагозащитных покрытий, эти эластомеры обеспечивают оптимальное демпфирование механических нагрузок в различных эксплуатационных условиях.

Влагозащитные покрытия горячего отверждения, не содержащие растворителей. Рассчитаны на быстрое отверждение при умеренных температурах (от 100 до 150 C; у многих покрытий этой группы существует три режима: 100, 120, $150^{\circ} \mathrm{C}$ ), обладают длительным сроком жизни в оборудовании нанесения покрытий погружением.

Упругопластичные влагозащитные покрытия, содержащие растворитель и отверждаемые при комнатной температуре. После отверждения обладают твердой, прочной поверхностью, облегчающей работу с ними и обеспечивающей повышенную износостойкость. Скорость отверждения может быть увеличена путем слабого нагревания [18]

К недостаткам силиконовых покрытий можно отнести:

- проблемы при нанесении: необходимо защищать растворитель от воздействия влаги, соблюдать меры предосторожности при нанесении погружением, ванна после использования должна находиться в закрытом состоянии;

- большая толщина нанесения (от 125 мкм), причем проведенные испытания показали, что для отверждения покрытия толщиной более 125 мкм потребуется увеличенное, по сравнению с заявленным производителем, время сушки;

- высокая стоимость.

\section{ИСПЫТАНИЯ ИМПОРТНЫХ ПОКРЫТИЙ}

Были проведены сравнительные испытания импортных влагозащитных покрытий на адгезию, влагостойкость и диэлектрические характеристики. Для проведения испытаний отобрано пять видов покрытий - 1А33 (уретановая основа) и UV-40 (сополимер полиакрилата и полиуретана) марки Humiseal; URETHANE 
(уретановая основа) и PLASTIK (акриловая основа) фирмы CRAMOLIN; пятым материалом стал отечественный лак УР-231 (ТУ 6-21-14-90), использовавшийся в качестве объекта сравнения. По результатам испытаний можно сделать следующие выводы:

- все покрытия удовлетворяют требованиям, предъявляемым к влагозащитным материалам по ТУ 6-21-14-90 «Лак УР-231. Технические условия» в части диэлектрических свойств;

- показатели адгезии у покрытий 1A33, UV-40 (по ГОСТ 15140-78) соответствуют показателям лака Ур-231. У остальных покрытий показатели адгезии ниже;

- наименьшее изменение веса под воздействием влаги выявлено у покрытия UV-40, оно ниже, чем показатели влагопоглощения лака ур-231. у остальных лаков влагопоглощение значительно выше.

Также было выявлено, что оптимальные режимы полимеризации не всегда соответствуют рекомендациям фирм-поставщиков. Предлагаемые ими режимы отверждения следует рассматривать как ориентировочные и проводить самостоятельную отработку режимов отверждения для обеспечения полной полимеризации покрытий и максимальной реализации защитных и других свойств покрытий.

В заключение хотелось бы сказать, что зарубежные покрытия имеют несколько лучшие характеристики и позволяют избежать многих затруднений. Но отечественные материалы заметно выигрывают у них в стоимостном отношении, что в конечном итоге оказывает положительное влияние на стоимость изготавливаемой продукции.

Также стоит заметить, что при грамотном подходе, правильном выборе материала, тщательной отработке и соблюдении технологических процессов в подавляющем большинстве случаев возможно получение стабильного качественного результата с применением отечественных влагозащитных покрытий. Тем не менее задача поиска новых материалов, свободных от основного недостатка отечественных покрытий - невозможности автоматического селективного нанесения - остается актуальной и должна быть решена.

\section{ЛИТЕРАТУРА:}

1. Левкина Н., Ванцов С., Медведев А. Влагозащитные покрытия печатных плат // ЭЛЕКТРОНИКА: Наука, Технология, Бизнес. 2018. № 7. С. 124-129.

2. ТУ 6-21-14-90. Лак УР-231. Техническое описание.

3. ГОСТ 20824-81. Лак ЭП-730. Технические условия.

4. ГОСТ Р МЭК 61192-5-2010. Печатные узлы. Требования к качеству. Часть 5. Доработка, модификация и ремонт. - М.: Госстандарт.
5. ІРС-7711/21А. Руководство по ремонту и доработке печатных узлов. Www.ipc.org

6. Поцелуев д. Абразив спешит на помощь. Технологичное решение для удаления влагозащитных покрытий ур-231, Э-30, ЭД-20 и парилена // Вектор высоких технологий. 2014. № 7 (12). С. 60-64.

7. Поцелуев д. Абразив спешит на помощь. Часть 2. Первая российская установка микроабразивного удаления влагозащитных покрытий "Борей» // Вектор высоких технологий. 2017. № 1 (30). С. 48-52.

8. Герасимчук В.А. Автоматизация процессов предприятия // Молодой ученый. 2016. № 11. С. 654-657

9. Полипараксилиленовое покрытие // Электронный ресурс http//www.bazalt1.ru/ (дата обращения 08.06.2018).

10. Большаков А. Передовые однокомпонентные полиуретановые влагозащитные покрытия Humiseal // Электронный ресурс https//ostec-materials.ru/tech_ lib/publications_otm/sborka-elektronnykh-moduley/ peredovye-odnokomponentnye-poliuretanovyevlagozashchitnye-pokrytiya-humiseal.php (дата обращения 08.06.2018).

11. Романова И. Влагозащитные покрытия. Материалы и оборудование // Печатный монтаж. 2010. №4. С. 22-33.

12. HumiSeal 1 B73 Acrylic Conformal Coating Technical Data Sheet // Электронный ресурс https//chasecorp.com/ humiseal1/wp-content/uploads/sites/12/2018/10/ 1B73-TDS.pdf (дата обращения 01.09.2018).

13. Federal test method standard "Paint, varnish, Iacquer, and related materials: methods of inspection, sampling and testing" // Электронный ресурс https// ru.scribd.com/document/122043875/PAINT-VARNISHLACQUER-AND-RELATED-MATERIALS-METHODS-OFINSPECTION-SAMPLING-AND-TESTING (дата обращения 08.06.2018).

14. HumiSeal ${ }^{\circledR}$ IA33 Urethane Conformal Coating Technical Data Sheet // Электронный ресурс https//chasecorp.com/ humiseal1/wp-content/uploads/sites/12/2018/10/ IA33-TDS.pdf (дата обращения 01.09.2018).

15. HumiSeal ${ }^{\circledR}$ UV40 UV Curable Conformal Coating Technical Data Sheet // Электронный ресурс https//chasecorp.com/ humiseall/wp-content/uploads/sites/12/2018/11/ UV40-TDS.pdf (дата обращения 01.09.2018).

16. HumiSeal UV40. Уретановое влагозащитное покрытие ультрафиолетового отвержения. Техническое описание - 2006 // Humiseal/.

17. Humiseal 1A33 уретановое влагозащитное. Технические данные // Электронный ресурс https//ostec-materials.ru/ (дата обращения 08.06.2018).

18. Информация о влагозащитных покрытиях торговой марки Dow Corning ${ }^{\circledR} / /$ Электронный ресурс https//ostec-materials.ru/(дата обращения 08.06.2018). 
17-19

СЕНТЯБРЯ 2019

САНКT-ПЕТЕРБУРГ

КВЦ “ЭКСПОФОРУМ" 